\title{
A QUESTÃO SOCIAL, O ESTADO E O MITO REDENTOR DA ACÇÃO LOCAL: lógicas e tensões presentes nas políticas e no trabalho social
}

\author{
Fernando Ilídio Ferreira*
}

\begin{abstract}
Resumo: Este artigo analisa e confronta diferentes lógicas e tensões que caracterizam a questão social nas sociedades contemporâneas. Em termos teóricos, discute as transformações do Estado, as políticas de descentralização e contratualização e a emergência de uma ideologia reticular (da organização em rede e em parceria), tendo em conta a sua influência na criação de uma espécie de mito redentor em torno da acção local. Apresenta também resultados de uma investigação etnográfica realizada num município rural do Norte de Portugal que revelam algumas tensões que enfrentam actualmente as políticas e o trabalho social, nomeadamente, entre a natureza societal e estrutural dos problemas e a intervenção pontual e individualizada das intervenções profissionais que manifestam, frequentemente, dilemas entre lógicas de ajuda e de controlo social.
\end{abstract}

Palavras-chave: questão social; Estado; acção local; rede; políticas e trabalho social.

\section{Introdução}

Embora lhe seja atribuído grande destaque nas sociedades contemporâneas, a "questão social" já se colocava, nos finais do século XIX, relacionada com o que eram considerados, na

\footnotetext{
* Professor e investigador da Universidade do Minho, Portugal. Doutor em Estudos da Criança, área de Estudos Socioeducativos. Director do Mestrado em Associativismo e Animação Sociocultural.E-mail: filidio@iec.uminho.pt
} 
altura, os disfuncionamentos da sociedade industrial. Ela já estava presente nas sociedades pré-industriais da Europa Ocidental, em termos de luta contra a mendicidade e a vagabundagem, mas foi com a emergência da sociedade industrial que se deu conta de uma forma de miséria associada ao desenvolvimento da riqueza e ao progresso da civilização. Mais recentemente, em um contexto ligado às transformações da sociedade industrial-salarial e do Estadoprovidência e ao fim de uma visão optimista do progresso, emergiu uma nova forma do "social” - a "nova pobreza”, nos anos de 1980, e a "exclusão social”, nos anos de 1990.

Desde então, tem-se assistido a uma profusão de programas e acções que colocam a "questão social” entre as prioridades da agenda política. A título de exemplo, podemos referir, no caso de Portugal, o Rendimento Mínimo Garantido, actualmente designado Rendimento Social de Inserção ${ }^{1}$, os Territórios Educativos de Intervenção Prioritária, os Projectos de Luta contra a Pobreza e a Exclusão Social, as Comissões de Protecção de Crianças e Jovens, os Conselhos Locais de Acção Social, o Mercado Social de Emprego, a Rede Social, etc. Sustentando-se numa retórica de descentralização, participação e autonomia, estas políticas configuraram o " local" - o espaço local, os actores locais e a acção local - como palco privilegiado da acção social territorializada e contratualizada ${ }^{2}$. O que é visado através desta abordagem das políticas públicas é o retorno do social à sociedade civil, fazendo apelo às solidariedades locais e ao trabalho em rede e em parceria.

Este renovado interesse pelo local ocorre num contexto de crise e de procura, por parte do Estado, de novas estratégias de relegitimação, face à emergência de fenómenos simultâneos de globalização e de relocalização, e também de "europeização das políticas públicas” (Muller, 1992; Muller, Mény, Quermonne, 1995). Neste contexto, o "contrato" transformou-se no próprio método de governação, revelando a passagem de um Estado administrador a um 
Estado mediador (Gaudin, 1999). Perante a crescente complexidade dos problemas do desemprego, da pobreza e da exclusão social e à incapacidade demonstrada e reconhecida pelos próprios poderes públicos centrais de fazerem face aos mesmos, gerou-se em torno do local uma espécie de mito redentor, sendo apontado como alternativa, quer à lógica neoliberal do mercado, quer à lógica burocrática e centralista do Estado. No entanto, este fenómeno de relocalização não se tem traduzido, de forma linear, como é entendido e sugerido frequentemente, num reforço do princípio da comunidade em detrimento dos princípios do Estado e do mercado. Em simultâneo, a partir da década de 1980 assistiu-se à propagação de políticas neoliberais à escala mundial e ocorreram profundas transformações ao nível do Estado e da acção pública, sendo significativo, na literatura, o uso de diversos qualificativos do Estado - "Estado animador” (Donzelot, Estèbe, 1994), "Estado supervisor” (Willke, 1991), "Estado parceiro" (Schweyer, 1996), entre outros.

A nova lógica contratual é assaz diferente da contratualização social de base colectiva estabelecida nas sociedades modernas, na qual o Estado-providência assumiu um papel fundamental. Historicamente, o “contrato social” constituiu mesmo a metáfora fundadora da racionalidade social e política da modernidade ocidental (Santos, 1998), correspondendo a um compromisso elaborado ao longo de mais de um século de lutas sociais, designadamente as lutas de classes no sistema de produção capitalista, e é constituído por regras escritas e não escritas, práticas, valores e instituições, em quatro grandes domínios: o direito ao trabalho, a redistribuição das riquezas, a protecção contra os riscos sociais e a promoção da igualdade de oportunidades (Petrella, 1995). Deste modo, o contrato social tornou-se a via de acesso à cidadania, quer pela extensão aos trabalhadores dos direitos cívicos e políticos, quer pela conquista de direitos económicos e sociais. Acontece, porém, que, desde a década de 1980, este modelo clássico do contrato social se 
transformou profundamente. Apesar de nunca se ter falado tanto em contratualização - das relações sociais, das relações de trabalho, das relações políticas do Estado com organizações sociais, etc. -, o sentido que lhe é atribuído hoje configura uma nova "contratualização liberal individualista” (Santos, 1998) que tem pouco a ver com a que foi fundada na ideia moderna do contrato social. As novas formas de contratualização passaram a assentar mais na lógica do contrato de direito civil entre indivíduos, e não na ideia do contrato social entre agregações colectivas de interesses sociais divergentes. Assim, "a nova contratualização é, enquanto contratualização social, um falso contrato, uma mera aparência de compromisso constituído por condições impostas sem discussão ao parceiro mais fraco no contrato" (Santos, 1998, p. 23).

Alguns autores têm afirmado que, à luz das novas lógicas de contratualização, a noção de contrato é utilizada mais em sentido metafórico do que em sentido jurídico. Por exemplo, Glasman (1999) defende que o "contrato" configura essencialmente uma démarche, uma espécie de "pedagogia de acção pública partenarial", através da qual o comprometimento assume uma natureza mais de "implicação" do que de "obrigação". Os procedimentos contratuais introduzem, assim, no âmbito da acção pública, um constrangimento mais incitativo que tutelar. A palavra de ordem é “implicação” (Nicolas-Le Strat, 1996): implicação no trabalho, na procura de emprego, no seu percurso de inserção, no seu projecto de formação. Por exemplo, à luz da nova abordagem contratual, os conceitos de trabalho e de emprego têm vindo a ser substituídos pela ideia de "empregabilidade", remetendo o problema, deste modo, para a esfera da responsabilidade de cada indivíduo. Nicolas-Le Strat sustenta que a sociedade civil nunca foi tão interpelada pela sociedade política como tem sido ao longo das últimas décadas, correspondendo o fenómeno do "implicacionismo" a uma tecnologia política incitativa de participação-implicação. No entanto, o sentido 
atribuído à participação, à implicação e à responsabilização é mais individual que colectivo, pressupondo que o que é necessário mudar são as condutas dos indivíduos - do desempregado, do pobre, do excluído - e não tanto os problemas do desemprego, da pobreza e da exclusão social, que têm uma raiz estrutural e societal.

As problemáticas da inserção e da inclusão, que se tornaram dominantes no campo das políticas sociais, tendem a desqualificar a análise dos mesmos em termos de desigualdades sociais. Como salientam Boltanski e Chiapello (1999), os traços positivos que um século de lutas operárias e de literatura revolucionária conferiu à figura do homem do povo - a coragem, a franqueza, a generosidade, a solidariedade - pendem a desaparecer nos discursos sobre a exclusão social, passando a imagem social do "excluído" a ser definida pela negação: os "sem" (sem palavra, sem abrigo, sem papéis, sem trabalho, sem direitos...). A exclusão social, tal como o desemprego, a pobreza, a toxicodependência, a sida, etc., é encarada como problema essencialmente pessoal e técnico que exige a "implicação" do indivíduo e a intervenção dos "profissionais de ajuda”, e não como problema estrutural, de natureza económica, social, cultural e política.

Com este enfoque na exclusão social, alguns temas sociológicos clássicos, como as classes sociais, as desigualdades e a exploração, têm sido secundarizados. Se, até finais dos anos de 1970, o debate sociológico se estruturou, sobretudo, em torno do tema das classes sociais e das desigualdades, pouco a pouco ele passou a estruturarse em torno do tema da exclusão. Mas, contrariamente ao modelo das classes sociais, os “excluídos” parecem ser considerados apenas uma colecção de indivíduos. Como sustentam Boltanski e Chiapello (1999, p. 436), “a exclusão ignora a exploração”, na medida em que é vista como um destino contra o qual cada um tem que lutar e não como o resultado de uma assimetria social em que alguns homens tiram lucro em detrimento de outros homens. Ou seja, 
[...] contrariamente ao modelo das classes sociais, no qual a miséria do "proletariado" repousava sobre a designação de uma classe (a burguesia, os detentores dos meios de produção) responsável pela sua “exploração”, o modelo da exclusão permite designar uma negatividade sem passar pela acusação (idem, ibidem, p. 426).

Em suma, o tema da exclusão relaciona-se mais com um “tópico do sentimento” do que com um “tópico da denunciação” (Boltanski, 1993).

Estamos, portanto, perante um conjunto de transformações que interrogam profundamente o próprio modelo de sociedade e de Estado. Castells (1998) sustenta que, durante o último quartel do século XX, se formou uma "sociedade em rede", resultante de transformações estruturais nas relações de produção, nas relações de poder e nas relações entre as pessoas. As relações de produção, embora continuem a reger-se pelas regras capitalistas, surgem agora com outras características que dão corpo a uma nova forma de capitalismo, o "capitalismo informacional”, tornando-se a flexibilidade o objectivo da "empresa em rede". Em termos de relações de poder, a principal transformação diz respeito à crise do Estado-nação como entidade soberana, pondo em causa as ideias de democracia e de política edificadas ao longo dos dois últimos séculos. A autoridade e a legitimidade do Estado foram postas em causa, pois a mundialização do capital e a descentralização da autoridade para os níveis regional e local engendraram uma nova geometria do poder e uma nova forma de Estado - o "Estado em rede”. No que concerne às relações interpessoais, as transformações decorrem essencialmente da crise do patriarcado, que desencadeou uma profunda redefinição da família, das relações entre os sexos, da vida sexual e da personalidade. A família patriarcal conheceu uma crise profunda, aparecendo formas embrionárias de família igualitária e de família transitória. Cada vez mais, a família nuclear é substituída, no seu papel primário de suporte afectivo e material, por uma "rede de indivíduos". 
Estas transformações estão associadas, como defendem Boltanski e Chiapello (1999), a um novo "novo espírito do capitalismo" que, a partir de meados de 1970, e de uma forma mais acentuada na década de 1980, se começou a apoiar, já não na organização hierárquica fordista, mas em novas formas de organização em rede, tornando incongruentes as análises dos fenómenos sociais feitas por referência aos modelos tradicionais do Estado, da sociedade e das instituições. Com base numa extensa análise da literatura de management, estes autores concluem que o período das três últimas décadas apresenta características muito diferentes das do período antecedente. No período de 1930-1960, caracterizado pelo management racional, orientado para a eficácia e para o progresso económico e social da grande empresa industrial, centralizada e burocratizada, o sistema racional e burocrático era considerado mais justo, na medida em que supunha um julgamento das pessoas dentro da empresa segundo critérios objectivos. A tónica era posta menos no empreendedor individual e mais na organização. A referência ao bem comum baseava-se na crença no progresso, na ciência e na técnica, na produtividade e na eficácia, e na solidariedade institucional entre as empresas e o Estado numa perspectiva de justiça social. Nos anos de 1990, as abordagens do management passaram a desvincular-se das tradicionais referências às estruturas, às funções e às relações hierárquicas e a aproximar-se mais das ideias de coordenação e de organização em rede. A vida social deixa de ser apresentada sob a forma de uma série de direitos e deveres, à imagem do mundo doméstico, ou sob a forma da carreira, própria do mundo industrial, passando a ser vista como um mundo conexionista feito de uma multiplicação de encontros e de conexões temporárias.

No que respeita à questão social, as políticas têm-se inspirado, em grande medida, nesta ideologia reticular - a organização em rede e o trabalho em parceria -, louvando as virtudes de uma acção social 
solidária e de proximidade ancorada nos territórios locais. Ou seja, retoricamente, a nova lógica contratual da acção pública substitui o princípio hierárquico pelo princípio da organização horizontal - a organização em rede. No entanto, estas transformações têm vindo a confrontar-nos com novos problemas e desafios, e também com a dificuldade de os compreendermos. Como se referiu anteriormente, algumas categorias clássicas da análise sociológica, nomeadamente os modelos das classes sociais e das instituições, foram questionadas por uma ideologia reticular e, como tal, é necessário elucidar as diversas lógicas em confronto e as tensões que atravessam as políticas sociais públicas contemporâneas. Embora se tenha verificado um incremento do "social territorializado", sustentado em discursos que apelam à iniciativa local e a modalidades de intervenção em rede e em parceria, o Estado não pode ser ignorado. Além disso, no caso de Portugal, é necessário reconhecer algumas particularidades, tendo em conta, designadamente, que só no início dos anos de 1970 o Estado se assumiu legalmente como provedor social principal, tendo desempenhado até então a posição de agente supletivo (Rodrigues, 1996, 1999).

Com este artigo pretende-se elucidar algumas destas lógicas das políticas sociais públicas contemporâneas, pondo em destaque algumas tensões que as atravessam, designadamente, entre a natureza estrutural e societal dos problemas e a intervenção pontual e individualizada das intervenções profissionais que, embora pretendam ser de ajuda, se constituem por vezes como práticas de controlo social.

\section{Lógicas e tensões presentes nas políticas e no trabalho social}

A análise apresentada nesta secção baseia-se em dados de uma pesquisa etnográfica realizada no âmbito da preparação de um 
doutorado concluído em 2003 na Universidade do Minho (Ferreira, 2005). A pesquisa foi realizada num município rural do Norte de Portugal - Paredes de Coura - e incluiu a observação participante e a realização de entrevistas a profissionais de instituições e serviços locais, nomeadamente educadoras de infância, técnicas de serviço social, uma educadora social, um médico, uma enfermeira e uma psicóloga.

Neste município, a população diminuiu acentuadamente na segunda metade do século XX. Em 1950, eram cerca de 16000 habitantes, enquanto, actualmente, são aproximadamente 9500, o que representa uma diminuição de cerca de 40\%. Esta regressão demográfica ficou a dever-se aos fenómenos de urbanização e emigração que afectaram profundamente esta e outras zonas rurais do país. Como a população que saiu para o estrangeiro e para as grandes cidades do litoral do país foram sobretudo jovens, actualmente, a população do concelho está bastante envelhecida. Por exemplo, em 1981, o número de crianças com menos de 15 anos ainda era superior ao de pessoas com mais de 60 anos, mas este fenómeno começou a inverter-se e, em 2001, a população com menos de 15 anos já correspondia a menos de um terço do total (de 3790 passou para 1192). Por sua vez, o número de habitantes com mais de 65 anos passou a representar mais do dobro do número de habitantes com menos de 15 anos $^{3}$.

Existindo ainda muitas situações de pobreza, principalmente nas localidades mais interiores do município, a Câmara Municipal e outros serviços e instituições locais - o Centro Regional de Segurança Social, as Instituições Particulares de Solidariedade Social (IPSS), designadamente a Santa Casa da Misericórdia e o Organismo Utilitário e Social de Apoio Mútuo (OUSAM), o Projecto de Luta contra a Pobreza e a Exclusão Social (Projecto Terras de Coyra), os Centros Sociais e Paroquiais recentemente criados em diversas freguesias, entre outros - intervêm na área social, sobretudo em 
termos de apoio a famílias e a pessoas idosas mais vulneráveis. Por exemplo, a Câmara Municipal implementou uma política social no domínio da habitação, apoiando a realização de obras e, em algumas situações, a construção de casa própria, oferecendo um projecto-tipo e a isenção de taxas, bem como reduções no preço dos materiais de construção.

\section{Entre a ajuda e o controlo: o enraizamento das ideias de assistência e de caridade}

A pesquisa de terreno implicou a realização de várias deslocações pelo interior do concelho, acompanhando as profissionais do trabalho social, e permitiu observar os contrastes entre a beleza das paisagens e as condições de pobreza e de solidão em que vivem ainda muitas pessoas, sobretudo idosas. O seguinte trecho ilustra um dia passado na companhia de três membros da equipa do Projecto de Luta contra a Pobreza e a Exclusão Social:

O dia estava muito chuvoso e frio. As estradas e os caminhos estavam em mau estado, o que fez com que o dia não tenha começado muito bem. Ao chegarmos ao primeiro local o carro ficou atolado na lama e só com a ajuda de alguns vizinhos idosos e de uma corda e pedras se conseguiu resolver o problema.

A primeira situação que estava prevista no plano de visitas era a de uma senhora idosa que vivia sozinha. 'Vão lá, que tem muito que ver’ - dissera-nos um vizinho com quem nos cruzáramos antes. Quando entrámos, directamente para a cozinha, verificámos o péssimo estado em que a casa se encontrava, agravado pela água da chuva que lá caía abundantemente. Não tinha água canalizada, não tinha casa de banho e apesar de o dia estar muito frio a lareira não estava acesa. Perguntaram-lhe se não tinha lenha, mas disse que sim. Talvez não tenha feito a fogueira porque era realmente na cozinha que mais água caía do tecto e se espalhava pelo chão. A Orlanda (técnica de serviço social) é quem toma a decisão de apoiar 
ou não a realização de obras. Neste caso decidiu imediatamente que o Projecto devia apoiar.

A relação entre os elementos da equipa com as populações locais está marcada por uma ideia de caridade. "Já era uma boa esmola”dizia uma pessoa referindo-se a uma ajuda para o forro da cozinha; "pelas alminhas" - dizia outra. Estas são expressões que as pessoas usam na sua relação com os elementos da equipa. Algumas esperam ajuda financeira. "Nós não somos da Segurança Social, não damos subsídios" - responde a Orlanda. A figura da "assistente social" é para estas pessoas uma esperança de obterem ajuda: "A minha filha tem uma casinha, teve uma ajuda da assistente social" confidenciou-nos uma pessoa idosa com quem conversámos no caminho" [notas de campo].

A intervenção social no âmbito deste Projecto abrange o apoio social a idosos, o acompanhamento psico-social de famílias, crianças, jovens e adultos, a promoção do artesanato regional e local, a realização de acções de formação profissional, entre outras, mas é no domínio da habitação que a intervenção é mais visível e para o qual é canalizada a maior parte dos recursos financeiros, contribuindo assim para a melhoria das condições habitacionais de várias pessoas. Contudo, os vários tipos de apoio prestados pendem a ser vistos como um acto de caridade e não como um direito de cidadania.

Em diversas visitas ficou patente que a expectativa das populações mais pobres em relação à visita das profissionais é a de se beneficiarem da caridade da "assistente social". Quando a Sandra (educadora de infância) e a Andreia (educadora social) circulam pelas diversas localidades do concelho, são identificadas como as “meninas da assistência” [notas de campo]. A própria instituição OUSAM, embora trabalhe essencialmente com crianças em Jardimde-Infância e em articulação com as famílias, também já é vista como “assistência”. Como dizem a Sandra e a Andreia, responsáveis pelo projecto "Dar Laços... Desatar Nós...", as pessoas já sabem que o OUSAM tem ligações com outras instituições e outros profissionais da área social e que "trabalha com os pobres": 
O OUSAM também é assistência, trabalha com os pobres. A ideia geral é de que o OUSAM trabalha com crianças, mas agora já há outras pessoas que sabem que nós temos uma técnica de serviço social, que faz apoio domiciliário, que trabalha com os idosos dos centros sociais, que quando surge algum problema com algum menino do Jardim-de-Infância e que é necessário a ligação com a família a técnica de serviço social está cá para isso. Portanto, há pessoas que já sabem as valências que o OUSAM tem. Sabem perfeitamente que nós somos do OUSAM, mas sabem que o OUSAM está muito ligado à Segurança Social, ao Projecto Terras de Coyra (Andreia, educadora social, e Sandra, educadora de infância).

Os trabalhadores sociais enfrentam, hoje, situações complexas que, frequentemente, se traduzem numa tensão entre uma intervenção que pretende ser de ajuda, mas que pode transformar-se, através de uma acção directa e deliberada ou em resultado de representações sociais a ela associadas, numa acção de controlo. As políticas e os trabalhadores sociais definem a intervenção por referência às ideias de “ajuda” e de "serviço”, no entanto, as representações e as práticas continuam a ser muito dominadas pelas ideias de "caridade" e "assistência", e até de "controlo", pois, frequentemente, a chegada de uma técnica de serviçco social a casa das famílias é percepcionada por estas como estando associada à existência de problemas, em relação aos quais vão ser “chamados à atenção”: “As pessoas associam a ideia de assistente social ao facto de alguma coisa não estar bem e irem ser chamados a atenção” (Júlia, educadora de infância).

Desde a década de 1990, com a proliferação de iniciativas de intervenção social inseridas em programas governamentais diversos, houve um incremento do trabalho social domiciliário. Se, por um lado, este trabalho tem dado visibilidade às condições de pobreza em que as pessoas vivem, contribuindo para a sua resolução, tem gerado, ao mesmo tempo, uma tendência para a invasão da esfera familiar privada. O apoio domiciliário tem-se tornado uma referência da acção social e, frequentemente, as famílias mais pobres recebem 
visitas de técnicos de diferentes entidades e de diversos projectos e programas. Quando participam em visitas domiciliárias, as educadoras de infância questionam, no entanto, a sua legitimidade para entrarem nos ambientes familiares, interrogando-se se ao fazêlo não estarão a "intrometer-se", a "apontar o dedo" e a "invadir a privacidade” das pessoas. O primeiro relato que a seguir se apresenta refere-se ao trabalho desenvolvido por uma educadora de infância que não tinha, na altura em que foi feita a entrevista, um grupo de crianças e uma sala de Jardim-de-Infância, dedicando-se por isso ao apoio específico a crianças nas salas de outras colegas e no próprio ambiente familiar, no âmbito do "Projecto CresSer"4; o segundo relato diz respeito a uma intervenção de uma educadora de infância, em colaboração com uma técnica de serviço social, junto da família de uma criança do seu grupo de Jardim-de-Infância:

Custou-me muito ter que ir trabalhar para casa porque tinha que levar um caixote com o material e trabalhar no quarto da mãe, porque apenas existia esta divisão e a cozinha, pois a casa ainda estava em construção e não tinha condições. E, por isso, eu sentia que invadia a privacidade daquela gente. Depois fui-me habituando. Às vezes estava a avó, a mãe e a tia a verem-me trabalhar com o menino. A mãe esteve sempre presente porque um dos objectivos era que ela aprendesse coisas simples para poder depois fazer com o menino: jogar a bola, fazer exercícios para desenvolver a motricidade, porque ele tinha as mãos, e ainda tem a esquerda, fechadas. Trabalhava-se a linguagem, com a apresentação de imagens. Depois eu até deixei lá ficar um caixote para ela guardar os brinquedos porque estava sempre tudo espalhado" (Liliana, educadora de infância).

Eu tinha o caso de uma menina que ingeria álcool e muito café e ao abordar o tema com a mãe esta não aceitou muito bem. Eu e a assistente social já tivemos alguns problemas com uma família, onde havia muitos problemas de higiene. Teve que se fazer uma intervenção em casa, o que não foi muito bem aceite, mas era preciso, porque as coisas melhoraram. Claro que alguém tinha que fazê-lo, mas, por vezes, também me interrogo se nós temos esse direito de intervir dessa forma numa família, entrar dentro das suas 
casas e apontar-lhes o dedo. Quando decorria esse caso eu cheguei a questionar-me com que direito uma pessoa faz isto, se não era um pouco de intromissão” (Júlia, educadora de infância).

Em consequência desta orientação para o trabalho domiciliário, as famílias pobres têm ficado mais expostas, não apenas em relação aos profissionais que realizam esse trabalho, mas também em relação aos vizinhos e à população em geral. Uma das famílias que mais exposta e conhecida ficou foi uma que tinha cinco filhos e vivia em condições de grande pobreza. Esta família tornou-se um "alvo" de todos os projectos e programas de intervenção social: "Toda a gente fala da [...], toda a gente conhece. Fala-se em pessoas carenciadas e toda a gente diz: é a [...]" (Andreia, educadora social, e Sandra, educadora de infância).

A proliferação de iniciativas no campo da acção social, designadamente, do apoio domiciliário, é hoje visível, por exemplo, quando se circula pelas estradas do concelho e se cruza frequentemente com viaturas de instituições e projectos como é o caso do OUSAM, dos Centros Socais e Paroquiais e do Projecto Terras de Coyra. A circulação dos trabalhadores sociais pelas localidades interiores do município dá visibilidade aos problemas, designadamente ao problema escondido da pobreza dos meios rurais e, como tal, estas acções têm um papel importante de denúncia e de melhoria das condições de vida das populações. Por outro lado, produz um efeito de exposição das famílias ao estigma de "pobres” e "excluídos", obrigando inclusivamente a que estas pessoas comprovem essa situação.

Ela tem vergonha de mostrar a própria casa e, por outro lado, não quer que o marido saiba que lá entrámos. [...] Já falámos com ela, porque achamos que é importante ela mostrar a casa onde vive para que as pessoas tomem consciência de que é mesmo importante resolver a situação da família, da habitação (Andreia, educadora social, e Sandra, educadora de infância). 
A obtenção, por parte dos profissionais, de provas relativas à condição de pobreza de algumas famílias torna-se um requisito necessário à intervenção, designadamente quando o que está em causa é a resolução do problema da habitação. Além disso, a "ajuda" pode tornar-se uma forma de produção ou acentuação dos rótulos de alcoólico, toxicodependente, ex-presidiário, pobre, excluído, beneficiário do rendimento mínimo, etc. Portanto, o trabalho social é um campo sensível, situado frequentemente entre a possibilidade de ajuda e de prestação de cuidados e o constrangimento da estigmatização e do controlo social.

\section{Políticas territorializadas e individualização da acção social}

No âmbito das políticas sociais públicas, a lógica da acção social territorializada emergiu em resultado do relativo insucesso das políticas sectoriais tradicionais. De acordo com Autès (1999), são seis as características principais das políticas sociais territorializadas: i) resultam de uma impulsão política, apoiandose numa administração de missão, na acção interministerial e na pilotagem intersectorial; ii) têm um carácter facultativo, pois não são generalizadas nem se impõem ao conjunto das situações e do território, apelando, antes, ao envolvimento voluntarista dos actores locais e assumindo um carácter experimental; iii) são políticas de anúncio de objectivos e prioridades, de apelo à opinião pública e de procura de implicação e convicção, não estando apenas em causa novos meios de acção pública, mas essencialmente novos modos de legitimação; iv) a palavra mágica destas políticas é o partenariado, procurando combinar a lógica política de missão e a lógica técnica da gestão; v) têm lugar num contexto de transformação das relações entre o Estado e o local, verificando-se, no entanto, que o Estado descentraliza essencialmente a gestão, mas não as funções que asseguram a construção das políticas públicas; vi) são políticas 
territorializadas, o que significa que são pilotadas localmente, mas, sobretudo, que têm por objectivo o território.

Porém, como mostram os dados empíricos que temos vindo a analisar, as políticas sociais territorializadas surgem em simultâneo com uma tendência de individualização da acção social. Os discursos dos trabalhadores sociais revelam uma maior orientação para os indivíduos do que para os territórios. E, nesta lógica de individualização, as palavras de ordem são o "encaminhamento" e o “acompanhamento”, tendo em vista a "educação” e a "organização” da vida das famílias. Em suma, o que é visado é a transformação das condutas, através de acções de formação no seio familiar, de organização doméstica, de economia do lar e de gestão de recursos, entre outras:

O meu trabalho é mais a nível de intervenção com as famílias. É um trabalho de acompanhamento (Helena, técnica de serviço social).

Nós não podemos estar a dizer a uma mãe ou a uma família que assim está mal, que deveria ser de outra maneira. Eles diriam: "Não, porque eu já criei os outros assim e vou continuar assim”. Então, como é que nós devemos fazer? Temos que dar a volta e valorizar os aspectos que... em vez de estar em casa todo o dia, sozinha, se a mandar para o Jardim-de-Infância tem esse benefício. Nunca podemos ir pela parte de desvalorizar (Andreia, educadora social, $e$ Sandra, educadora de infância).

As acções/actividades do projecto (Dar Laços... Desatar Nós...) baseiam-se em visitas domiciliárias, acompanhamento familiar e o necessário trabalho em parceria.

Fazemos um acompanhamento das famílias e crianças ao nível da saúde, educação, acção social, planeamento familiar, habitação...

Em determinados casos existe também um acompanhamento psicológico (certas crianças e adultos).

Outra acção necessária é a avaliação do desenvolvimento da criança, fazendo a despistagem de atrasos e quando se justificar proceder a encaminhamentos para entidades especializadas. 
Assim, acompanhamos certas crianças e sua família a determinadas consultas de especialidade (como seja consultas de desenvolvimento, terapia da fala entre outras [...].

Desenvolvemos acções de intervenção ao nível da organização doméstica, economia do lar e gestão de recursos [...].

Quando necessário são feitas acções de formação no seio familiar, nas áreas de planeamento familiar, preparação para o parto, cuidados básicos a ter com bebés, higiene e saúde... (Andreia, educadora social, e Sandra, educadora de infância).

Neste contexto, as reflexões sobre a sociedade, as desigualdades e as injustiças sociais parecem estar ausentes. Em contrapartida, abundam as descrições em torno de "casos” individualizados. Mesmo quando estas educadoras fazem referência ao trabalho em parceria, conferem-lhe o sentido individual da relação que estabelecem com cada família ou pessoa apoiada. Como nos foi dado observar, as reuniões da equipa do Projecto "Dar Laços... Desatar Nós...” são dedicadas essencialmente a conversas sobre "casos” e "situações” individuais, revelando não apenas a referida tendência de controlo social, designadamente em torno do cumprimento do "acordo de inserção" por parte do beneficiário do Rendimento Mínimo, mas também a proximidade e a afectividade com que os trabalhadores sociais falam sobre os mesmos:

A Elisabete.

Aquela dos caracolinhos?

É do Rendimento Mínimo?

Sim.

Então vamos pô-los finos (ameaça de corte do Rendimento Mínimo se o acordo de inserção não for cumprido).

A senhora onde fomos fazer aquela formaçãozinha?

Sim, a do bebé.

O marido é aquele que a deixou e fugiu com outra?

A Bruna ainda está hospitalizada [notas de campo]. 
O "contrato de inserção", mediante o qual o beneficiário se compromete, por exemplo, a realizar uma acção de formação profissional, a levar os filhos à escola para cumprirem a escolaridade obrigatória, etc., constitui um exemplo da nova lógica contratual individualista. Apesar de se basear no princípio da negociação, o parceiro mais fraco do contrato não está em posição de escolher, e este se transforma, por isso, num contrato obrigatório.

\section{Entre o mito educativo de longo prazo e a urgência da intervenção}

O trabalho social orienta-se predominantemente para casos e situações individuais considerados urgentes e, como tal, pressiona para a realização de acções de curto prazo. Como diz a psicóloga da "equipa operacional" do Projecto Terras de Coyra, a intervenção é feita "em cima do acontecimento" e o profissional que a realiza é "como um bombeiro":

É um bocado fruto das solicitações que chegam e do professor que telefona e diz "este miúdo é urgente, gostava que viesse aqui". [...] Ir respondendo ao que é mais urgente; é nessa base que mais tem funcionado. Tem que ser com um bocado de criatividade, telefonar a ver o que há sobre isto, sempre um bocado em cima do acontecimento. É como um bombeiro (Lúcia, psicóloga).

O "mito educativo" (Ion, 2000) constituiu-se historicamente num dos sustentáculos fundamentais da acção social e das ideologias profissionais. Através de uma acção educativa orientada para a transformação das condutas, ou seja, ensinando as pessoas a tornarem-se autónomas, a decidirem por elas próprias e a integraremse na sociedade, a acção social sempre visou reinserir na sociedade aqueles que dela se tinham afastado - os "vagabundos" no Antigo Regime, os "miseráveis" no século XIX e os "excluídos" nos finais do século XX (Castel, 1995). No entanto, esta ideologia educativa do trabalho social, que pressupõe uma perspectiva de longo prazo, 
é contraditória com a urgência da intervenção no terreno. Na realidade, o trabalho social pretende, sobretudo, gerir os excluídos sem esperança, na medida em que estes procuram cada vez mais ajudas precisas (ajudas financeiras, estágios pré-profissionais, etc.) e não tanto entrar num processo pedagógico.

Como este trabalho de urgência, de curto prazo, é incongruente com o objectivo da produção de mudanças profundas, pois estas são, no campo social e educativo, de longo prazo, isso leva a que os trabalhadores sociais desenvolvam uma consciência de que têm que “valorizar os pequenos ganhos” para não se sentirem "frustrados” no seu trabalho: "Como técnicos, temos que gerir expectativas e saber lidar com algum grau de frustração" (Andreia, educadora social, $e$ Sandra, educadora de infância).

No entanto, um dos principais problemas que se colocam actualmente aos trabalhadores sociais é o da própria continuidade dos projectos, devido à precariedade da sua própria situação profissional. Encontrando-se frequentemente em situação de estágio profissional, saltando de estágio em estágio e de projecto em projecto, o seu trabalho não tem garantias de continuidade.

O nosso trabalho... são coisas que só se vêem resultados a longo prazo, não é? E aquelas pequenas coisas que nós vemos e que dizemos assim "realmente aquilo mudou, melhorou" é um pequeno nada que temos que valorizar, como técnicos, porque se não também nos sentimos um bocado frustradas. [...] Temos que nos agarrar a alguma coisa pequena para sentirmos que vale a pena, se não as pessoas começam a desinvestir (Andreia, educadora social, e Sandra, educadora de infância).

É um bocado desmotivante pensar que quando eu dominar isto tudo, se calhar vou-me embora. [...] Acho que na área social devemos trabalhar a longo prazo (Lúcia, psicóloga).

Nesta abordagem comunitária, nós às vezes numa primeira visita não conseguimos muito; numa segunda já conseguimos um bocadinho 
mais; numa terceira mais ainda. As pessoas começam a ver que são os amigos que entram na casa delas, não são os intrusos, são pessoas amigas que os querem mesmo ajudar. E portanto com este trabalho de persuasão contínuo e permanente vamos conseguindo que a pessoa pense que nós estamos realmente interessados em ajudá-los. Se são situações pontuais em que a gente lá aparece uma vez, não dá confiança (Fernanda, enfermeira).

A continuidade do trabalho é essencial, em primeiro lugar, porque implica a criação de uma relação empática com as pessoas, de modo a obter-se a sua confiança, o que constitui, na sua essência, um processo lento; em segundo lugar, porque, aos olhos dessas pessoas, os trabalhadores sociais com quem interagem quotidianamente passam a constituir-se como portadores de esperança. Como referem as profissionais, um dos principais objectivos do seu trabalho é "elevar a auto-estima”, pois as pessoas "não têm sonhos, não têm projectos de vida":

Vamos fazer visitas domiciliárias em que se tenta fazer uma educação para a saúde relativamente a situações, dar conselhos, tentar que as pessoas também se aproximem mais do centro de Saúde, tentar uma relação até mais empática para que as pessoas nos recebam bem e que também aceitem bem a nossa presença e para sentirem também que com o nosso apoio podem mudar alguma coisa na vida delas. [...] É preciso que a gente lhes dê também um bocadinho de auto-estima. Elevar a auto-estima. E elas começam a sonhar um bocadinho mais, porque estas pessoas não têm sonhos, não é. São pessoas que vivem o dia-a-dia e não se lembram do dia de amanhã. Não têm sonhos, não têm projectos de vida. E, portanto, é preciso a gente também tentar que elas construam um projecto de vida" (Fernanda, enfermeira).

Na sua condição de “especialistas da escuta e da palavra” (Ion, 2000, p. 121), a acção dos trabalhadores consiste, frequentemente, em ouvir as pessoas idosas que vivem em condições de solidão e que pretendem não tanto projectar o futuro, mas narrar e reviver memórias do passado: 
Estivemos em casa de um casal, ele com setenta anos e ela com perto de sessenta, durante quase uma hora, praticamente todo o tempo a ouvi-los, sobretudo à esposa, a falar dos filhos, dos netos e de um bisneto que moram em Lisboa. A casa estava repleta de imagens de santos e de fotografias dos familiares ausentes, porque emigraram. Era uma forma de matar a saudade e a solidão. Passaram o tempo a mostrar-nos fotografias dos casamentos, do filho que tinha falecido há cinco anos e que desde então nunca mais tinha ficado boa da cabeça. A casa estava limpa e arrumada, tinha tijoleira no chão, um quarto de banho completo. "Tudo feito pelos meus filhos. São muito meus amigos. Dizem-me para não usar roupa preta, mas eu não consigo, parece que não tenho luz”, desabafava a senhora. Era visível, no entanto, a satisfação com que, acompanhada pelo marido, mais calado, nos mostrava a casa. Os membros da equipa elogiavam: "Está tudo muito bem, muito arrumadinho". A senhora ria, feliz, e continuava a mostrar [notas de campo].

Ora, após um projecto de intervenção social ter contribuído para a melhoria da auto-estima, de ter criado confiança e expectativas, o seu fim pode revelar-se extremamente penalizador para as pessoas envolvidas. Como frequentemente a intervenção social se caracteriza mais pela dimensão relacional e afectiva do que pela dimensão material, o fim de um projecto pode levar a que os progressos conseguidos tenham um retorno não apenas para o nível em que as pessoas se encontravam inicialmente, como, pior ainda, à acentuação do sentimento de abandono e de exclusão.

\section{As lógicas do trabalho em parceria: entre o programa e o projecto}

Como se referiu anteriormente, as próprias educadoras, quando alargam o seu campo de intervenção para o contexto familiar, são vistas como as “meninas da assistência”. Por um lado, 
esta identificação está associada ao facto de elas efectuarem visitas domiciliárias com outras profissionais das áreas social e da saúde, designadamente as técnicas de serviço social da Segurança Social e do Projecto "Terras de Coyra" e a enfermeira do Centro de Saúde, pretendendo beneficiar, com esta colaboração, de outras fontes de legitimidade profissional e institucional.

Nos primeiros contactos não poderíamos ir só eu e a Andreia, não é? Então tentámos arranjar uma pessoa que fosse uma forma de entrar na família. E foi a Helena (técnica de serviço social do OUSAM), porque eram famílias que já tinham algum contacto com o OUSAM. Noutros foi a Margarida (técnica de serviço social da Segurança Social). Noutros foi a enfermeira Fernanda (do Centro de Saúde). Sempre que a enfermeira Fernanda está disponível e nós julgamos que é importante, ela vai connosco (Andreia, educadora social, $e$ Sandra, educadora de infância).

Por outro lado, pretendem assumir um papel de mediação, alertando e envolvendo os diversos serviços e instituições das áreas política, social, da educação e da saúde, quando o problema ultrapassa as suas possibilidades: "Somos um bocado intermediários, um elo de ligação” (Andreia, educadora social, e Sandra, educadora de infância). As relações inter-institucionais são estabelecidas, por exemplo, com a Segurança Social quando há situações que envolvem beneficiários do Rendimento Mínimo, com o Projecto "Terras de Coyra" quando o problema concerne à habitação, com o Centro de Saúde, quando os problemas identificados dizem respeito à área da saúde, com a psicóloga quando os problemas têm a ver com crianças nos contextos escolar e familiar.

Efectivamente, da parte das profissionais observa-se uma predisposição para a cooperação, à qual não será alheia a influência exercida por alguns projectos de intervenção social e comunitária desenvolvidos neste município desde os anos de 1980, nomeadamente o projecto OUSAM, que se tornou e ainda é hoje reconhecido a nível nacional como pioneiro neste domínio. 
O projecto OUSAM teve origem no Centro de Saúde local, no início dos anos de 1980, constituindo-se em 1985 como Instituição Particular de Solidariedade Social. A sigla OUSAM significa, como já se disse, Organismo Utilitário e Social de Apoio Mútuo, mas na escolha do nome houve, como foi referido pelos fundadores, uma intenção de fazer um trocadilho com a ideia de "ousar”. Desde a sua origem, esta instituição desenvolve actividades com crianças, famílias e comunidades nas freguesias mais isoladas do concelho, valorizando os recursos e os saberes locais.

A filosofia que se desenvolveu em Paredes de Coura foi a valorização daquilo que as pessoas sabem, do tomar consciência das condições em que se vive e de que o desenvolvimento pode passar por aí, desde que a gente tenha consciência crítica do que é o papel da pessoa, da família, naquele contexto [...]. Havia actividades que procuravam envolver as famílias, por exemplo, algumas avós que poderiam contar histórias a todo o grupo, ou então o grupo das crianças poderia ir a casa de uma criança quando houvesse um acontecimento que 0 justificasse, por exemplo, quando a vaca de algum familiar parisse, ou então poderiam apanhar castanhas todos juntos... Portanto, com isto procurava-se não só realizar esses trabalhos mas também valorizar aquilo que as crianças e as suas famílias conheciam [...]. Um dos princípios fundamentais que ali se desenvolveu foi o de tentar partir das vivências daquelas crianças e famílias para o desenvolvimento de um processo de aprendizagem para o próprio desenvolvimento da criança, em termos de competências, etc. Ou seja, os temas a abordar têm que ver com a vida: a vaca, as vindimas, etc. (António, médico).

Esta filosofia do Projecto está relacionada com a experiência do seu principal impulsionador-o António, médico de Saúde Pública - que já participava, desde os anos de 1960-1970, em movimentos associativos e em processos de intervenção comunitária. Antes de chegar a Paredes de Coura, em 1982, já tinha desenvolvido, entre 1975 e 1981, um trabalho baseado na "cooperação intersectorial” e em formas de "integração de serviços locais”, "prestando atenção aos grupos mais vulneráveis". Reflectindo, hoje, sobre esse trabalho 
de cooperação entre instituições e serviços locais ligados à Saúde, à Educação, à Autarquia, ao Serviço Social, ao Emprego, etc., este médico considera que foi pioneiro, quer para ele próprio, quer para o sector da Saúde Pública, "porque se ensaiaram formas de trabalho em equipa e de cooperação entre cidadãos, técnicos e grupos, com base na participação das pessoas em cada freguesia” (António, médico).

Com efeito, quer os profissionais que já trabalharam no OUSAM, quer os que chegam de novo, como é o caso da psicóloga do Projecto "Terras de Coyra" e da enfermeira do Centro de Saúde, enfatizam a cultura de solidariedade, colaboração e parceria que encontram em Paredes de Coura.

Desde que trabalho em Paredes de Coura, e pelo contacto com outras pessoas que já cá estiveram, o trabalho em parceria não é algo deste momento, destas novas medidas; já vem sendo um hábito, em Paredes de Coura, o trabalho em parceria. [...] Há concelhos onde é difícil trabalhar em parceria. Eu penso que talvez pelo facto de Paredes de Coura estar um tanto ou quanto isolado, entre aspas, dos outros, as pessoas que cá estão têm mesmo de se organizar, sentem essa necessidade de trabalhar em conjunto para uma só causa, no caso do Rendimento Mínimo, da Comissão de Protecção de Menores. Isto é agora, neste momento, mas antes isto já acontecia, porque o Centro de Saúde desenvolvia um projecto e pedia a colaboração do OUSAM, pedia à Câmara Municipal, e as pessoas participavam. [...]. Quando cheguei aqui isto já acontecia e o OUSAM é um exemplo disso; nasceu precisamente de um trabalho de conjugação de esforços entre vários serviços e até entre vários técnicos. [...] Havia uma filosofia de equipa, uma co-responsabilização pelas diferentes áreas (Margarida, técnica de serviço social da Segurança Social que trabalhou no OUSAM entre 1994 e 1998).

Eu acho que aqui há muita solidariedade. Eu via, por exemplo, no meu estágio que havia elementos de instituições que não se davam e, portanto, não articulavam, não faziam trabalho. Aqui ainda não vi uma situação dessas, acho que há uma cultura de solidariedade (Lúcia, psicóloga). 
Algo que fez a diferença no meu trabalho aqui foi o facto de haver uma abertura muito grande de todas as entidades e de todas as instituições, um trabalhar em conjunto, sempre [...]. Eu vim de [...], onde havia muitos problemas, essencialmente políticos que, no fundo, afastavam as instituições. Não se conseguia fazer articulação nenhuma. Era toda a gente voltada de costas umas para as outras. E neste trabalho comunitário, e eu especialmente que sou enfermeira, precisamos mesmo do apoio de todas as instituições (Fernanda, enfermeira).

No entanto, desde os anos de 1990, estas perspectivas têm sofrido transformações, sobretudo com o formalismo decorrente dos programas governamentais da área social. Aparentemente, começaram a predominar as preocupações com aspectos gestionários em detrimento do trabalho no terreno, designadamente no âmbito das “parcerias” que hoje "proliferam por decreto”.

Aquilo que ao longe nos pode parecer um conjunto de representantes de diferentes sectores de mãos dadas entre si, pode corresponder, quando se olha de mais perto, a uma série de pessoas algemadas umas às outras e acorrentadas a um sistema que não lhes permite tomar iniciativas para além do que está estipulado para os "utentes normais" (cumpridores das normas). [...] Se as parcerias proliferarem por decreto em diferentes ministérios, criando-se múltiplos grupos de trabalho ao nível local, sem qualquer integração entre si, corre-se ainda o risco caricato de vários daqueles que antes se empenhavam em trabalho no terreno passarem a ocupar quase todo o seu tempo saltando de reunião em reunião, com muitas caras comuns mas temas diferentes, cada vez mais indisponíveis para o trabalho no terreno em que estavam envolvidos (Ferreira, 1998, p. $198)^{5}$.

Consequentemente, os trabalhadores sociais mais experientes têm-se visto confrontados com um acréscimo de trabalho 
administrativo, de gabinete, tendendo o trabalho de terreno a ficar entregue aos profissionais mais jovens, que estão a iniciar a sua actividade profissional e se encontram frequentemente em situação de estágio. Num “Encontro de Projectos do Programa Ser Criança”, que o OUSAM organizou em Janeiro de 2002, no qual participaram seis projectos de diversas localidades do Norte do país, verificou-se que estavam sobretudo envolvidos nos mesmos jovens sociólogos, psicólogos, técnicos de serviço social, educadores sociais, entre outros [notas de campo]. Estas transformações revelam um efeito paradoxal da "lógica de programa" que tem vindo a instalar-se: os trabalhadores sociais mais experientes tornam-se "gestores de programas" e o trabalho de terreno, que é o mais complexo e sensível, é realizado pelos mais jovens e sem experiência. No entanto, esta situação parece ser encarada como natural, sendo inclusivamente reconhecido um estatuto mais elevado a quem realiza um trabalho de gabinete.

De facto, uma das tensões que se coloca com maior acuidade no actual período, marcado pelo incremento de "programas" de âmbito nacional na área social, é a continuidade dos "projectos" locais em que os trabalhadores sociais estão envolvidos. O Estado procura impulsionar a acção social através de programas de política social, no âmbito dos quais se desenvolvem os projectos locais. Com o término desses programas, os projectos locais vêem-se obrigados a adquirirem a sua própria base de sustentação, mediante processos de participação. Acontece, porém, que, na lógica de "programa", os profissionais envolvidos nesses projectos tendem a dedicar-se predominantemente ao preenchimento burocrático de formulários, ao invés de promoverem esses processos locais de participação.

Surge, além disso, uma tendência para os projectos locais reproduzirem linguagens e práticas uniformes dos programas nacionais. As noções de “risco”, “população alvo”, “grupo alvo”, etc. têm sido muito utilizadas nesses formulários e também no discurso 
dos trabalhadores sociais, revelando uma maior subordinação a lógicas instrumentais e moralistas do que a lógicas de participação e empowerment. Por exemplo, no formulário de candidatura de projectos ao referido Programa Ser Criança, a definição das "problemáticas de intervenção" é feita a partir de uma lista que enumera um conjunto de "carências", "défices" e outras situações, designadamente "famílias numerosas” e "desestruturação familiar”, as quais são definidas como "problemas" a partir de um juízo moralista sobre o que é considerado uma família "normal”. Gera-se assim uma lógica de racionalização, através da qual as linguagens tendem a uniformizar-se e a descontextualizar-se, revelando, frequentemente, uma subordinação do trabalho social a perspectivas carencialistas e até preconceituosas e moralistas.

\section{Conclusão}

A questão social não diz respeito apenas às margens da sociedade. Com o processo de industrialização e da modernidade liberal, ela deixou de se circunscrever a populações marginais, assumindo a forma de uma "vulnerabilidade de massa” (Castel, 1995, p. 160). Embora desde sempre se tenha colocado explicitamente sobre as margens da vida social - sobre os "vagabundos" antes da revolução industrial, sobre os "miseráveis" do século XIX, sobre os "excluídos” de hoje -, a questão social inscreve-se numa dinâmica social global. Através de um "efeito boomerang” (idem, ibidem, p. 21), os problemas postos pelas populações encalhadas na periferia de uma formação social fazem retorno para o seu centro.

Esta vulnerabilidade de massa está estreitamente associada à crise da sociedade industrial-salarial. O trabalho assalariado, que ocupa hoje a grande maioria dos activos e ao qual estão ligadas as protecções contra os riscos sociais, constituiu durante muito tempo uma das situações mais incertas, indignas e miseráveis. Era 
assalariado quem não tinha nada para trocar para além da força dos seus braços. Cair no assalariado era cair na dependência. Após muitas transformações, o trabalho assalariado atingiu nos anos de 1960 o lugar de matriz de base da sociedade industrial-salarial moderna, passando a envolver quase toda a população e a definir a própria identidade social. O emprego assalariado tornou-se "o grande integrador” (Barel, 1990). Contudo, a esta função integradora do trabalho sucedeu o emprego selectivo da sociedade pós-industrial (Foucauld, Piveteau, 1995), ou seja, o fenómeno da lute des classes deu lugar a um novo fenómeno da lute des places (Gaulejac, Taboada-Léonetti, 1994). Os próprios conceitos de trabalho e de emprego, de natureza estrutural, têm vindo a ser substituídos pela ideia de "empregabilidade", remetendo o problema para a esfera da responsabilidade de cada indivíduo, que tem de lutar por um lugar no mercado de trabalho, independentemente da posição social e das qualificações que possui.

Ora, o debate sobre a questão social não pode ignorar este pano de fundo em que as características do trabalho estão profundamente transformadas. Estando estreitamente associada ao esboroamento da sociedade salarial e aos fenómenos de desemprego e de precarização, a exclusão não corresponde apenas a situações individuais, mas a "uma angústia colectiva face ao risco de perda do emprego e das regalias sociais” (Paugam, 1997, p. 35). Como sustenta Bourdieu (1988), hoje a precariedade está em toda a parte, agindo directamente sobre aqueles que toca (e que deixa sem condições de se mobilizarem) e indirectamente sobre todos os outros, pelo medo que suscita e que é metodicamente explorado pelas estratégias de precarização, como a introdução do princípio da flexibilidade. Em suma, "a precariedade inscreve-se num modo de dominação de tipo novo, baseado na instituição de um estado generalizado e permanente de insegurança visando coagir os trabalhadores à submissão, à aceitação e à exploração” (idem, ibidem, p. 118). Da mesma 
maneira que o pauperismo do século XIX estava inscrito no coração da dinâmica da primeira industrialização, hoje a precarização do trabalho é um processo central, comandado pelas novas exigências tecnológico-económicas da evolução do capitalismo moderno. O desemprego, a precarização do emprego e a vulnerabilidade social são as consequências consideradas necessárias dos novos modos de estruturação do trabalho, em termos de flexibilidade, polivalência e competitividade.

Num mundo que se tornou intensamente competitivo, sustentado numa ideologia do sucesso, da competência e da performance, apontando no sentido da responsabilização e da realização pessoal, a noção de classe social, que fornecia uma representação de conjunto da vida social, foi fortemente questionada, tornando-se necessário desocultar os efeitos destas transformações. Um destes efeitos é a "desinserção social" (Aubert, Gaulejac, 1991), que consiste num duplo processo confluente. O primeiro é a corrida à performance no seio da organização produtiva; o segundo é a psicologização do mundo, que gera sentimentos de culpa, humilhação, desesperança, inutilidade e incompetência. À luz de uma ideologia de "realização pessoal e profissional" e de um ideal de perfeição associado ao indivíduo autónomo, responsável e empreendedor, as pessoas que não dispõem de recursos para satisfazer todas estas exigências sofrem um processo de desinserção social. E, embora, frequentemente, o insucesso não tenha a ver com uma incapacidade ou uma inadaptação individual, a pessoa vê-se como única responsável pela sua situação, não se reconhecendo como vítima de uma distorção estrutural mas antes culpável de uma falta pessoal. Em suma, num mundo dominado pela competitividade e pela ideologia da performance, da excelência e do sucesso, não há ganhadores sem perdedores.

A questão social coloca-se, hoje, portanto, em estreita 
correlação com o esboroamento da condição salarial, na medida em que esta condição, que veio estruturar quase por inteiro a nossa formação social, se encontra fragilizada. Neste contexto, o "social” deixou as margens da sociedade, dos indivíduos inadaptados ao progresso, para se tornar numa questão que diz respeito à sociedade no seu conjunto. A questão social passou a caracterizar-se, assim, por uma preocupação em manter a coesão de uma sociedade ameaçada de fractura. Perante esta ameaça, que paira sobre as pessoas e que tem sido caracterizada em termos de precariedade, vulnerabilidade, exclusão, etc., os temas das classes sociais e das desigualdades, que marcaram a agenda sociológica dos anos de 1960-1970, passaram, em grande medida, a ser substituídos, a partir dos anos de 1980-1990, por uma focalização na questão do "laço", do "vínculo", bem como numa representação do problema em termos de conexão e de desconexão, de exclusão e de inclusão.

Enquanto, na sociedade industrial-salarial, a função integradora era desempenhada pelo trabalho, na sociedade dita pós-industrial é a "rede" que é proclamada como a garantia da coesão social. As políticas sociais públicas - do emprego, da luta contra a exclusão e outras - passaram a apelar aos "serviços de proximidade” (Laville, 1992; Amaro, 1997), às "redes" de solidariedade, nomeadamente às solidariedades familiares, às solidariedades das organizações e instituições sem fins lucrativos, como é o caso das cooperativas, mutualidades, associações, misericórdias, fundações e, de um modo bastante difundido em Portugal, das IPSS. No entanto, assiste-se à desestruturação e fragilização dos sistemas de protecção social de carácter universal e à emergência de uma lógica de ajuda localizada e individualizada. Ou seja, a perspectiva da "luta contra as desigualdades sociais" deu lugar à perspectiva da "luta contra a exclusão social”, mas, enquanto a primeira se apresentava como uma finalidade de justiça social, a segunda apresenta-se como uma finalidade paliativa (Canário, Alves, Rolo, 2000). 
Para além das acções localizadas e individualizadas, a questão social exige intervenções em diferentes âmbitos e escalas. Se bem que a questão social se coloque, hoje, de modos diferentes e se assista a uma revitalização da economia social e solidária, o Estado não pode produzir um discurso apologético da participação e da autonomia locais, abandonando o seu papel provedor e tornando-se apenas supervisor e avaliador. Ou seja, torna-se necessário pensar e agir em diferentes escalas, de modo a incrementar a cidadania de proximidade à escala local; a criar regulações, convenções e instituições à escala mundial, para garantir, através da coordenação de políticas, uma vigilância e uma acção política internacional; e a revitalizar o Estado à escala nacional, de modo a corrigir assimetrias, desigualdades e injustiças que afectam territórios e populações concretos.

Desde o início dos anos de 1990, a própria crise do Estadoprovidência mudou de natureza, entrando numa nova fase em que, para além dos graves problemas de financiamento e dos disfuncionamentos dos seus aparelhos, são os próprios princípios organizadores da solidariedade e a própria concepção dos direitos sociais que estão em causa. Nos anos de 1970, a crise do Estadoprovidência era essencialmente de ordem financeira; nos anos de 1980, de ordem ideológica e de legitimidade e, nos anos de 1990, de ordem filosófica, estando em causa, neste último período, o problema da cidadania. Hoje, a questão social é acompanhada por esta crise filosófica e, portanto, já não estamos numa situação igual à da década de 1980, na qual era exigida a relegitimação do Estado e da acção pública (Rosanvallon, 1995). Enquanto nessa década o Estado era posto em causa pelas ideias de Estado mínimo e de privatização, a partir da década de 1990, a intervenção pública encontrou toda a sua justificação perante as fracturas sociais que se agravaram. 


\section{Notas:}

1 Em Portugal, o programa do Rendimento Mínimo Garantido foi criado em 1996 (Lei n 19-A/96, de 29 de Junho) e a sua aplicação foi generalizada em 1997. É uma medida que se insere no âmbito do debate europeu sobre política social de combate à pobreza e à exclusão.

2 Em grande medida, a abordagem territorial, contratual ou partenarial das políticas públicas, sustentada nas ideias de "diálogo social", "negociação”, "parceiros sociais”, etc., foi introduzida pela Comissão Europeia, através do Livro Branco da Política Social Europeia (Comissão Europeia, 1994) e de diversos programas de financiamento. O III Quadro Comunitário de Apoio, no período de 2000-2006 (Comissão Europeia, 2000), continuou a dar primazia às "acções integradas de base territorial", convocando expressões como "redes sociais”, "parcerias”, "partenariado”, “acções comunitárias”, “aç̧ões de animação sociocultural", "solidariedades locais" e "redes territoriais de desenvolvimento local".

3 Fonte: Instituto Nacional de Estatística, Recenseamentos Gerais da População.

4 Trata-se de um projecto da instituição OUSAM inserido no "Programa Ser Criança”, promovido pelo Ministério do Trabalho e da Solidariedade Social.

5 O autor é o médico que impulsionou o projecto OUSAM no início dos anos de 1980.

The social issue, the State and the redeeming myth of local action: reasonings and tensions between policies and social work

Abstract: This article analyzes and confronts different reasonings and tensions which characterize the social issue in contemporary societies. In theoretical terms, it discusses the transformations of the State, the decentralization and contractual policies, and the emergence of a reticular ideology (the network and partnership 
organisation), taking into account their influence on the creation of a type of redeeming myth of local action. It also presents the results of an ethnographic investigation carried out in a rural municipality in the North of Portugal, which reveals some current tensions facing policies and social work, namely between the societal and structural nature of problems and the punctual and individualised professional interventions that frequently show dilemmas between care reasonings and social control.

Key words: social issue; State; local action; network; social work and policies.

\section{Referências}

AMARO, R. R. Serviços de proximidade em Portugal. Lisboa: Ministério para a Qualificação e o Emprego: Direç̧ão-Geral do Emprego e Formação Profissional, 1997.

AUBERT, N.; GAULEJAC, V. Le coût de l'excellence. Paris: Seuil, 1991.

AUTÈS, M. Les paradoxes du travail social. Paris: Dunod, 1999.

BAREL, Y. Le grand intégrateur. Connexions, Paris, 1990, n. 56, p. 85100.

BOLTANSKI, L. L'amour et la justice comme compétences. Paris: Métailié, 1993.

; CHIAPELLO, È. Le nouvel esprit du capitalisme. Paris: Gallimard, 1999.

BOURDIEU, P. Questions de sociologie. Paris: Minuit, 1988.

CANÁRIO, R.; ALVES, N.; ROLO, C. Territórios educativos de intervenção prioritária: entre a "igualdade de oportunidades" e a "luta contra a exclusão”. In: BETTENCOURT, A. M. et al. Territórios educativos de intervenção prioritária: construção ecológica da acção educativa. Lisboa: Instituto de Inovação Educacional, 2000. 
CASTEL, R. Les métamorphoses de la question sociale: une chronique du salariat. Paris: Fayard, 1995.

CASTELLS, M. L'ère de l'information (v. I): la société en réseaux. Paris: Fayard, 1998.

COMISSÃO EUROPEIA. Livro branco da política social europeia: como avançar na união. Bruxelas: Comissão Europeia, 1994.

. QCA - Quadro Comunitário de Apoio III: Portugal 2000-2006. Lisboa: Direcção-Geral do Desenvolvimento Regional, 2000.

DONZELOT, J.; ESTÈBE, P. L'état animateur: essai sur la politique de la ville. Paris: Esprit, 1994.

FERREIRA, A. C. Exclusão social, desenvolvimento e cidadania escrevemse de maneira diferente consoante a vida das pessoas e comunidade que têm por dentro. In: PINTO, J. M.; DORNELAS, A. (Coord.). Perspectivas de desenvolvimento do interior: colóquio promovido pelo Presidente da República durante a Jornada da Interioridade. Lisboa: INCM, 1998, p. 189-199.

FERREIRA, F. I. Education, social mediation and community development: an ethnographic research in a rural area. Community Development Journal, Oxford, 2008 [doi: 10.1093/cdj/bsn022].

O local em educação: animação, gestão e parceria. Lisboa: Fundação Calouste Gulbenkian, 2005.

FOUCAULD, J.-B.; PIVETEAU, D. Une société en quête se sens. Paris. Odile Jacob, 1995.

GAUDIN, J.-P. Gouverner par contrat: l'action publique en question. Paris: Presses de Sciences de Po., 1999.

GAULEJAC, V. ; TABOADA-LEONETTI, I. La lutte des places: insertion et désinsertion. Paris: Desclée de Brouwer, 1994.

GLASMAN, D. Réflexions sur les «contrats» en éducation. Ville Ecole Intégration, Paris, 1999, n. 117, p. 70-111. 
ION, J. Le travail social à l'épreuve du territoire. Paris: Dunod, 2000.

LAVILLE, J.-L. Les services de proximité en Europe. Paris: Syros, 1992.

MULLER, P. Entre le local et l'Europe. La crise du modèle français de politiques publiques. Revue Française de Science Politique, Paris, 1992, 42(2), p. 275-297.

; MENY, Y. ; QUERMONNE, J.-L. Politiques publiques en Europe. Paris: L’Harmattan, 1995.

NICOLAS-LE STRAT, P.L'implication: unenouvelle base del'intervention social. Paris: L’Harmattan, 1996.

PAUGAM, S. Revenu minimum et politiques d'insertion. Comment la pauvreté se régule dans les sociétés européennes. Intervenção Social, Lisboa, 1997, n. 15/16, p. 15-46.

PETRELLA, R. L'Europe entre l'innovation compétitive et un nouveau contrat social. Revue Internationale des Sciences Sociales (RISS), Paris, 1995, n. 143, p. 21-34.

RODRIGUES, F. Assistência social e políticas sociais em Portugal. Lisboa: ISSS, 1999.

RODRIGUES, F. Pobreza e exclusão social: configuração e perspectivas, a intervenção e formação dos profissionais sociais. In: DER HOVEN, R. V.; NUNES, M. H. (Coord.). Desenvolvimento e ação local. Porto: Fim de Século, 1996, p. 11-34.

ROSANVALLON, P. La nouvelle question sociale: repenser l'étatprovidence. Paris: Seuil, 1995.

SANTOS, B. S. Reinventar a democracia. Lisboa: Fundação Mário Soares: Gradiva, 1998.

SCHWEYER, F.-X. Vers un état partenaire? In: PAUGAM, S. (Dir.). L'exclusion: l'état des savoirs. Paris: La Découverte, 1996, p. 487506.

WILLKE, H. Trois types de structures juridiques. In: MORAND, C. A. (Dir.). L'état propulsif. Paris: Publisud, 1991, p. 65-94. 